\title{
RECONCEPTUALISING THE THIRD SPACE OF LEGAL TRANSLATION: A STUDY OF THE COURT OF JUSTICE OF THE EUROPEAN UNION*
}

\author{
EDWARD CLAY, PhD Candidate \\ College of Arts and Law \\ University of Birmingham, UK
}

ORCID: https://orcid.org/0000-0002-2468-4641

\section{KAREN MCAULIFFE, Professor of Law and Language \\ School of Law \\ University of Birmingham, UK}

\footnotetext{
* The research for this paper was generously supported by the European Research Council (FP7 - Project Number 313353) and The Wolfson Foundation. The authors would like to thank Professor Aleksandra Cavoski for her feedback on earlier versions of this paper, as well as the anonymous reviewers of this journal edition for their constructive and helpful feedback. The authors also thank all of the interview respondents and colleagues at the Court of Justice of the European Union who engaged so helpfully with the research. This paper was written during the 2020 COVID-19 lockdown, a difficult time to be productive: Professor McAuliffe would like to express special thanks to her young son for being (mostly) patient while Mama worked instead of playing with him; Edward Clay would especially like to thank his parents for their support and Tonderai Immanuel for keeping him sane throughout the process.
} 
Edward Clay \& Karen McAuliffe: Reconceptualising the third space...

\title{
k.mcauliffe@bham.ac.uk
}

\section{ORCID: https://orcid.org/0000-0002-1314-0139}

\begin{abstract}
This paper explores the concept of legal translation as a Third Space through the lens of the 'multilingual' Court of Justice of the European Union (ECJ). In many ways legal translation at that Court fits readily with the characterisation of translation as a Third Space. Due to complex internal production processes the ECJ produces texts which are undoubtedly hybrid in nature, and which exhibit distinctive features on a lexical and textual level marking them out as a product of cross-fertilisation of influences from source and target languages and legal cultures. Even the teleological approach taken towards legal reasoning at the ECJ occupies a space outside the strict confines of the texts involved. Both the processes and the product of the ECJ's language system appear to bear all the hallmarks of translation as a Third Space. However, translation at the ECJ also challenges the concept of a Third Space. The prevailing definitions of translation as a Third Space fail to effectively conceptualise additional nuances of the specific nature of drafting and the complex nature of translation at the ECJ. This paper uses original empirical data to demonstrate that translation at the ECJ places constraints on the undefined, vague and fluid nature of the Third Space, warping the forces at work within that space. In this regard, rather than an amorphous space, the Third Space is better thought of as a determinate area which is delimited by elements of translation process which constrain it. This adapted framing of the Third Space can consequently be used to better understand and illustrate the dynamics at play in other areas of legal translation where the current concept of the Third Space is equally inadequate for encompassing the specific nature of translation practices which impact on that space-in-between.
\end{abstract}

Keywords: legal translation; translation theory; translators; ECJ; CJEU; legal cultures; Third Space; teleological interpretation;

\section{Introduction}

This paper explores the concept of legal translation as a Third Space in the context of translation theory, and investigates whether the environment of legal translation at the Court of Justice of the European Union (ECJ) occupies such a Third Space. That environment of legal translation includes explicit translation processes as well as "hidden" 
layers of translation involved in the production of ECJ case law (McAuliffe 2016), and the distinctive legal reasoning processes employed by that multilingual Court. The ECJ is unique among international courts insofar as it produces case law in up to 24 languages, applicable throughout 27 member state legal systems. The factors of production of that multilingual case law - comprising collegiate judgments, drafted in a language which is usually not the mother tongue of the drafter, finalised in secret deliberations and which have, as the case proceeds, undergone many permutations of translation into and out of up to 23 languages - undoubtedly fulfil many of the criteria of a Third Space. The culture of compromise at all stages of production of that case law results in the creation and use of a hybrid language with autonomous terminology, consistent with the idea of a Third Space. However, in this paper we argue that while translation at the ECJ does exist in a Third Space, it also challenges the concept of the Third Space owing to the specificities of the Court's processes and hierarchical linguistic structures. Translation at the ECJ places constraints on the undefined, vague and fluid nature of the Third Space, warping the forces at work within that space. The analysis in this paper delineates the concept of the Third Space in the context of legal translation at the ECJ. This concept, as more precisely defined, may also be applicable to other multilingual legal contexts. We argue that if translation at the ECJ is to be considered a Third Space, it must be understood as constituting a special case. This paper presents an overview of the theory underpinning the concept of the Third Space, its relation to translation theory and its application to legal translation, before examining how the specific setting of translation at the ECJ conforms to the notion of legal translation as a Third Space. It then sets out the various elements inherent in the ECJ's processes and structures which challenge the current concept of the Third Space by setting constraints on the freedom of action in that space and distorting the dynamics by which it is usually characterised.

In this paper we draw on original empirical data, namely interviews carried out at the ECJ between 2012 and 2016, to highlight the features of the Third Space in relation to the production of ECJ case law, as well as to support our claim that translation at the ECJ challenges the notion of the Third Space as currently articulated. Interviews are uniquely suited to uncovering factors that impact on the culture of an institution, and can shine a light on processes within an organisation which are otherwise invisible (McAuliffe, Muntean and 
Mattioli, forthcoming 2021). The interviews included in this study formed part of a wider research methodology for a larger research project: the Law and Language at the European Court of Justice (LLECJ) project. That project investigated the impact of multilingualism and translation on ECJ case law ${ }^{1}$. The interview techniques used in the interviews allowed for restraint and a focus on listening - respondents were allowed to tell their stories with little interference or guidance from the interviewer (Reinharz 1992: 21). No interview schedule was followed, instead, open questions, based on pre-identified themes were used. Those themes included: processes and functioning of various departments (including judges' chambers) at the ECJ; the roles of various actors in the production of that Court's multilingual jurisprudence; translation procedures and processes; checking and quality assurance processes; the impact of language and culture on work processes in a multilingual institution; the role, autonomy and power of translators. Where respondents were not receptive to open questioning, more focused, closed questions were used. Using such interview techniques resulted in responses that were also very open, and that themselves raised issues relating to concepts beyond the project's research questions. This approach allowed us to analyse the interviews from the perspective of the Third Space, which highlighted aspects of translation at the ECJ that set it apart from other legal translation contexts. The interview sample for this paper consisted of 43 interviews in total (3 judges, 21 référendaires and 19 lawyer-linguists). All interviews were conducted in Luxembourg, in person, and anonymously in accordance with Chatham House Rules ${ }^{2}$. The majority of the respondents agreed to an audio recording of the interview and they were provided with transcripts of the interviews. They were free to edit those transcripts as they saw fit, before the researcher proceeded with coding (in NVivo) and analysis of the data. Quotes from interviews are included in this paper only where they are indicative of a majority view.

\footnotetext{
${ }^{1}$ European Research Council, FP7 - Project Number 313353. See the project website, www.llecj.karenmcauliffe.com, for further details, including results and other outputs. ${ }^{2}$ When a meeting is held under the Chatham House Rule, participants are free to use the information received, but the identity of participants may not be revealed.
} 


\section{Theoretical Framework: What is the 'Third Space'?}

The notion of a Third Space was first developed in the field of postcolonial theory in order to address questions of identity and belonging through language (Bhabha 1994). By envisaging a sphere outside the rigidities of binary cultural structures, a more fluid space can be created where "we will find the words with which we can speak of Ourselves and Others" (Bhabha 2006: 209). Occupying the gap which divides cultural spheres, the Third Space represents a 'space-inbetween' where two or more cultures interact and where the dominant culture and language can be subverted (Wolf 2000: 141). This concept of a Third Space can also be applied to broader situations of linguistic and cultural interaction and transfer, in which the translator plays a pivotal role. Through translation a new 'hybrid' language occupying this space in between is forged through a process of "culturo-linguistic layering" (Mehrez 1992: 121). It is therefore within this Third Space, located between two cultural and linguistic poles, that hybridization comes into being. Taking Bhabha's original concept of the Third Space from post-colonial studies and expanding it to encompass a broader spectrum of culturo-linguistic mixing and recombination will inevitably produce hybridity. These complementary notions of Third Space and hybridity, which this paper seeks to explore in the context of translation at the court of justice of the European Union, place the translator at the centre of a cultural interaction, operating within a liminal space in order to mediate between different languages and divergent cultures. Spivak characterises translation as a process where "meaning hops into the spacy emptiness between two historical languages" (2012: 313), envisaging a vaguely defined site for the negotiation of linguistic and cultural dynamics. This concept has long been attractive to translation studies scholars: the translator is often characterised as moving constantly back and forth between two poles rather than being a fixed and static entity simply processing a source text and producing a target text (e.g. Cronin 2000). Operating within this space characterised by a hybridity of language and culture, the translator becomes "shaped by a sort of exile, involved in, yet still on the borderline of, culture" (Wolf 2000: 142). Rather than imagining translation as a bridge between cultures, it is within this dynamic Third Space where cultures encounter one another and new meanings are created. This interpretation fits more readily with a perspective of communication as intercultural rather than 
cross-cultural (see Schaffner \& Adab 2001). Whereas the concept of cross-cultural communication envisages a simple one-directional transfer of information across linguistic and cultural boundaries - a conveyance of ideas from one place to another within a binary framework - the concept of a Third Space is intercultural in that it is built around the idea of a "process of fertilisation" from each language and culture in all directions, resulting in a product which is linguistically and culturally distinct (Schäffner \& Adab 2001: 167). Indeed, this concept reflects the reality of today's multicultural world made up of heterogeneous groups where hybrid texts are "a natural result of our international, intercultural, globalised lives" (SnellHornby 2001: 208). EU texts in particular, are considered to be intercultural and hybrid because of the unique manner in which they are created, since "in the course of... multilingual negotiations (with or without the involvement of translation), the specific linguistic and cultural conventions get mixed up and infiltrate each other" (Schäffner and Adab 2001).

The development of translation theory as a discipline and empirical findings in that area largely reflect and confirm the notion of translation constituting a Third Space. The advent of descriptive translation studies (Toury 1995) triggered the development of a branch of research armed with methodological techniques to allow the findings from individual studies to be replicated and compared in order to provide a more general picture of translation behaviour and the norms in operation during the practice of translation. This approach brought about research examining the specific features common to translated texts, embodied in Toury's "laws of translation" (2012). The "law of growing standardization" (Toury 2012: 267) states that source text patterns in translations are often disrupted and the target text tends to standardize culture-specific or specialised items into more general items in the target language. In opposition to this, the "law of interference" (Toury 2012: 274) refers to source text features being copied over into the target text. The concurrent application of these conflicting laws implies that the translated text will have distinctive characteristics and must exist in a sphere beyond the binary framework of source and target language.

Numerous other studies have shown that translated texts differ from non-translated texts in various ways, both because features of the source language tend to "shine through" (Teich 2003) and processes inherent in the practice of translation often alter aspects of the target 
language through explicitation, simplification and normalisation (Chesterman 2004). These subtle differences between translated and non-translated texts have been attested to by a range of corpus-based studies. For example, the Covert Translation project sought to use diachronic-contrastive analyses to determine the influence of English on German translations in various different genres (House 2006). It produced several studies demonstrating that a range of German textual norms, such as sentence-initial concessive conjunctions and expressions of modality, had been subverted in German translations of English texts as a direct result of the source language's influence (House 2006; Becher, House \& Kranich 2009). Moreover, when examining Greek translations of English popular science texts, Malamatidou (2016) shows that the use of the passive voice in the Greek translations is proportionally higher than in non-translated Greek texts as a result of the more common use of the passive voice in the English source texts. Indeed, that study argues that the translations employ a specific language "characterised by a frequency of the passive voice that is somewhere between" the source and target languages (Malamatidou 2016: 27, emphasis added). Although a translation usually appears as the product of the target language, the complex interaction between competing linguistic, semantic and cultural requirements results in a code which is effectively a blend of the source and target languages, and bears features of both - the code is situated 'somewhere between' ${ }^{3}$. This empirical evidence, demonstrating differences between translated and non-translated texts, indicates that translations occupy a distinct space outside the strictures of both source and target languages: a Third Space.

How then does this notion of the Third Space apply more specifically to the case of legal translation? Translation of the law needs to accurately reflect the content of the source text while also respecting the linguistic norms of the target language and the legal conventions of the target language legal system. The task of the legal translator is to use a legal text in one language to create an equivalent legal text in another language such that a legal decision-maker will arrive at the same conclusion irrespective of the language version used (Ainsworth 2014). Legal translation thus forms its own discrete category due to the

\footnotetext{
3 'Code' is a neutral term used in linguistics to designate any grammatical system with distinctive characteristics, including languages or subvarieties within them (cf. Malamatidou 2016: 5).
} 
unique challenges associated with it, which are not shared by other areas of translation for special purposes (Felici 2010). Unlike other special-purpose texts, legal texts do not have "a single agreed meaning independent of local context" (Steiner 1998). There is no universal legal language, or even terminology: each legal system has a unique legal language, linked to a view of the social order, within the relevant state, region or organisation. That legal language, by expressing legal norms, determines the way in which the law is applied, and shapes the function of law in that society. Legal translators thus need a clear understanding of complex legal concepts in each of the legal cultures involved, and a sound grasp of how and why legal professionals write in the way they do, so that they can adopt the same sensitivities of language when translating legal texts. To do this effectively, they engage in a "culture mediation" to overcome the problems inherent in translating legal texts (Wagner \& Gémar 2014: 2). In addition to cultural transfer (where the focus is on translation as a process of negotiation between texts and cultures), legal translation is concerned with legal transfer, insofar as it must take account of the statement of the law that is at the heart of any legal text (McAuliffe 2015). A translation of a legal text should produce the same effects in the target legal system as it does in the source legal system (Šarčević 1997: 72). Constantly confronted with problems of imperfect or partial equivalence between two legal systems and "conceptual voids" due to the "system bound nature of legal terms" (Biel 2014: 42), legal translators are obliged to engage in the highly complex process of transferring and re-expressing the original text by navigating the space in between. By envisaging the legal translation process as a Third Space, the result of such a process will inevitably be a hybrid of the contributing factors from both source and target directions.

While some see hybrid texts as a transitory stage in the development of new text types, which eventually cease to be hybrid (Tirkkonen-Condit 2001: 261; Schäffner and Adab 2001: 295), others claim that translations are in fact "agents of dehybridisation" (Pym 2001: 205) since they mark the line between (at least) two languages and cultures, thereby perpetuating the separation and purity of those languages and cultures (Pym 1996). However, according to Simon's definition of hybridity through translation, the label of 'hybrid texts' should be applied only to those texts which "draw attention to themselves as the products of two separate meaning systems" (2011: 50). Legal translations are inescapably the product of the interaction 
between two or more different legal structures and cultures - they are, by definition, created in this intermediate space of cultural negotiation. Translated legal texts are therefore imbued with hybridity, which should not be negatively equated to contamination but to the positive product of "mixed identities and creative interference" (Simon 2011: 49). Despite this, much condemnation has been directed at the hybrid nature of the language used by the EU institutions, which is frequently derided as "Eurospeak" (Koskinen 2000: 55; Vareine 2015). However, errors aside, criticisms often levelled at hybrid multilingual law as constituting 'translationese' are usually unfounded, and betray insufficient knowledge of the complex conceptual network of EU law and multilingualism-related constraints which are involved in the EU's linguistic processes (Biel 2014: 73). While a hybrid text produced in the context of EU law may not conform to the standard norms and conventions of the target language and culture, it is widely "accepted in its target culture because it fulfils its intended purpose in the communicative situation" (Schäffner \& Adab 2001: 169). The question addressed henceforth in this paper does not therefore focus on the merits or shortcomings of the hybrid language used at the European Court of Justice, but instead aims to determine to what extent the ECJ's language processes and outcomes conform to the descriptions of the Third Space as outlined above, and whether those processes in fact challenge the concept of that Third Space. As a consequence, this paper fills a gap in the literature by reinterpreting a theoretical framework conceived in post-colonial studies and commonly used in translation studies, and applying it to legal translation at the ECJ for the first time. In so doing, it is possible to draw comparisons with other translation contexts and gain a deeper insight on how legal translation at the ECJ stands alone as a special case.

\section{Legal Translation at the ECJ: A Third Space}

The multilingual environment of the EU institutions is a fascinating point of study in this context since legal translation of EU texts represents both a "cross-cultural and interlingual communicative act" and a "complex human and social behaviour" (Cao 2007: 5). The European Court of Justice is particularly interesting since much of the 
linguistic and cultural interaction in the 'space-in-between' takes place behind closed doors, in behind the scenes drafting and translation practices, and deliberations which historically have been secret. In a number of ways, the legilinguistic practices undertaken at the ECJ are an example par excellence of legal translation as a Third Space. Both the manner in which case law is created and the end product itself are unavoidably hybrid in nature. This section explores the various facets of this hybridity and consequences of legal translation at the ECJ occupying the Third Space.

\subsection{How the ECJ language system operates}

The ECJ is, from the outside at least, a truly multilingual institution. It produces case law in up to 24 languages ${ }^{4}$ and interactions between parties to a case and the Court can take place in any of the EU official languages. Judgments delivered by the ECJ are inevitably the product of the multilingual and multi-layered processes and procedures which are undertaken within the organisation itself. Understanding the processes of production of that multilingual case law is important when conceiving of hybridity in (legal) translation: if the process itself takes place in a Third Space, then the product will necessarily be hybrid. Translation is a key factor in the production of ECJ case law. Although the ECJ is a multilingual, multicultural institution, in order for it to be able to function efficiently, it uses a single working language: French. All applications lodged, and documents coming into the ECJ are translated, by the Court's Translation Directorate, into French, before being processed further (McAuliffe \& Trklja 2018). At the other end of the process, judgments and orders are translated from French into the other 23 EU official languages. The ECJ's Directorate General for Multilingualism is responsible for translation and interpretation ${ }^{5}$.

\footnotetext{
${ }^{4}$ The 24 official languages of the EU: Bulgarian, Croatian, Czech, Danish, Dutch, English, Estonian, Finnish, French, German, Greek, Hungarian, Italian, Irish, Latvian, Lithuanian, Maltese, Polish, Portuguese, Romanian, Slovakian, Slovenian, Spanish, Swedish.

${ }^{5}$ While interpretation undoubtedly impacts on intercultural communication in the oral part of proceedings before the ECJ, consideration of interpretation in this context is beyond the scope of this paper, which focuses solely on the written production and translation of ECJ case law.
} 
Within that Directorate, 23 language units, plus a 'cellule' for the Irish language ${ }^{6}$ cover each EU official language. The various language units are responsible for translating all of the documents relating to a case before the ECJ that are required to be translated under the applicable rules: this can include, the request for a preliminary ruling from a national court, Member State observations, interventions by third parties, procedural documents and Advocates General's opinions (where relevant) ${ }^{7}$. At the end of the process, those units are responsible for translating the judgment (McAuliffe 2012). Given the multi-layered process and the multitude of official EU languages, there is a broad range of permutations of translation into and out of up to 23 different languages (McAuliffe 2008). The translation system at the ECJ is a mixed one: direct translation (i.e. from one EU official language to another EU official language) is preferred whenever possible, but the system also provides for 'indirect' or 'pivot' translation through one of the ECJ's designated 'pivot languages' (French, English, German, Spanish, Italian and Polish) (McAuliffe 2017). The result of each one of these translation stages in every language pair involved is undoubtedly the product of great effort and compromise to reach a social, political and legal harmonisation through the use of language common to multilingual EU legal translation in all institutions. Moreover, rather than occurring only at fixed points in the process (i.e. the beginning and end of procedure), translation is an ongoing practice which occurs at various stages during the Court's work on a case, and which can sometimes even be 'hidden' (McAuliffe 2016). The cultural, legal, and linguistic blending of elements also occurs in the space created by other processes established by the ECJ itself.

\footnotetext{
${ }^{6}$ For reasons related to recruitment and staffing, Irish has been allocated a 'cellule' rather than a full language unit.

7 The Advocate General (AG) delivers a reasoned opinion on a case, prior to deliberations on and delivery of the judgment. Article 20 of the Statute of the ECJ allows that Court to determine case without an AG's opinion where no new points of law are raised (Treaty on the Functioning of the European Union Protocol (No 3) On the Statute of the Court of Justice of the European Union, OJ C 202, 7/6/2016, p. 210 229).
} 
Edward Clay \& Karen McAuliffe: Reconceptualising the third space...

\subsection{Third Space Highlighted by Process of Production}

a. Hybrid Texts

It is well known that ECJ judgments, drafted in French and subsequently translated into up to 23 other languages, are collegiate documents. Judgments are drafted by a single judge rapporteur, together with their team of legal assistants, known as référendaires. The French language draft judgments are then deliberated on by a chamber of judges in secrete deliberations (ostensibly conducted in French). The agreements and compromises reached during those secret deliberations are then reflected in the final version of the relevant judgment, drafted in French. Thus, ECJ judgments are, by their very nature, hybrid documents.

The judgments are from the Court, not an individual judge. Yes one judge writes the initial judgment... but in fact it is usually drafted by a référendaire in consultation with the judge... but then [the judges in a chamber] deliberate and discuss... so the final version comes from the court but with multiple inputs along the way (référendaire);

Of course judgments are a collegiate effort. In the sense that they are finalised by a chamber of judges together in deliberations but also before the deliberations. In my cabinet at least we work very much as a team [judge];

I think you could say judgments are hybrids, yes. There are multiple contributors all putting their own input to the text in the end. But the judges take responsibility in the end. (référendaire)

Furthermore, the majority of référendaires, and indeed judges, are not native French speakers. Empirical data demonstrates that working in a second or third language affects the drafting process, and that référendaires tend to apply methods of reasoning common to their own national jurisdiction, or the jurisdiction where they received their legal education (McAuliffe 2016), thus introducing a further element of hybridity into the process.

Well of course when I'm first working on a draft I think in [mother tongue] even if I'm writing in French. I suppose I just translate how I am arguing into French (référendaire); 


\section{Comparative Legilinguistics 45/2021}

...all my reasoning and thinking about the case is done in my own language and then I translate the gist of what I want to say into French (référendaire);

I start off planning the arguments in my own language, and then put them on paper in French (référendaire).

Finally, the pivot translation process means that some target texts are at the end of a translation chain and may therefore bear the features of both the original source text and the pivot language version. Indeed, the term "multilinguistic superdiversity" has been proposed in order to capture the extent of the hierarchical relationships between languages and the relations between them in this context (McAuliffe \& Trklja 2018). These atypical aspects clearly situate the ECJ's translation process outside the usual binary translation framework made up of a fixed and non-hybrid source text and a target text arrived at on the sole basis of that single original source text.

\section{b. Legal Reasoning}

Evidence of a Third Space can also be found by analysing the process of judicial reasoning at the ECJ. On the face of it, one would expect such judicial reasoning to be inherently multilingual. After all, this is a Court which produces case law in up to 24 languages, sitting (and deliberating) as a Full Court of 27 judges, a Grand Chamber of 15 judges or in Chambers of three or five judges, all of whom have been educated in different legal systems and who specialise in different areas of the law. However, as Bengoetxea points out "by opting for a common working language, the Court preserves multilingualism as an institution but becomes a monolingual decision-maker" (2016). The exception to that rule is when the ECJ carries out genuine comparison of language versions of legislation in order to reach a more comprehensive interpretation of the relevant norm of EU law - although such comparison often merely confirms an interpretation reached by other means (cf. Section 3.2c). The monolingual decision-making referred to by Bengoetxea is reflected in empirical data, in which the notion of a 'French bubble' at the ECJ emerges time and again:

On the outside it's multilingual... but inside the Court it's not really multilingual. All that matters is the French version [of a judgment]. The cabinets are in a French bubble (lawyer-linguist); 
Edward Clay \& Karen McAuliffe: Reconceptualising the third space...

There's a kind of French bubble. As long as the French version [of a judgment] says what [the relevant chamber] want it to say, that's all that matters (lawyer-linguist);

I suppose you could talk about a French bubble. Certainly all our focus is on getting the French version [of a judgment] right (référendaire);

Getting the French version of a judgment right is key (judge).

That is not to say that the ECJ does not engage in multilingual reasoning. According to Bengoetxea that comes later in the process, at the translation stage (cf. Section 4.3).

Even in that 'French bubble' the interaction of (legal) cultures in the 'space-in-between' of the ECJ's legal reasoning processes, creates new meaning. Bengoetxea describes the ECJ as a potential laboratory for comparative law and comparative legal cultures, but notes that comparative judicial dialogue at that Court usually tends towards the supranational, rather than the transnational. i.e. the ECJ is interested in "declaring, drawing from, and developing autonomous concepts and independent meaning to ensure effective and uniform application of [EU] law" rather than having any desire to link with national legal traditions (2016). Thus this unique monolingual but multicultural legal reasoning, carried out in a multilingual setting, creates a Third Space in which divergent legal cultures, underpinned by different languages but working within the framework of an aspirationally uniform EU law can develop autonomous legal principles, and a unique method of reasoning and interpreting that law.

\section{c. Teleological Interpretation}

When it comes to interpreting the EU's multilingual legislation, the ECJ also occupies a space beyond the confines of the source and target texts. The ECJ's teleological approach to interpretation of EU law is well established, including in the event of discrepancies between language versions of EU legislation (cf: Bengoetxea, MacCormick, and Soriano 2001; van Calster 1997) ${ }^{8}$. That teleological approach focuses on the purpose of the relevant provision, rather than on a strictly linguistic interpretation, and is what Baaij calls the Court's dominant first-order

\footnotetext{
${ }^{8}$ Unlike ECJ judgments, all language versions of EU legislation are considered equally authentic (Council Regulation No 1 Determining the Languages to be used by the European Economic Community OJ 17, 6/10/1958. 385-386 (as amended)).
} 
argument in dealing with diverging language versions of legislation (Baaij 2018: 167). Baaij also describes another ECJ first-order argument as systemic or contextual interpretation, which considers a provision in the broader context of EU law relevant to that provision (2018: 167). Such contextual interpretation is generally employed by the ECJ alongside the teleological method, and together they comprise what Solan refers to as the "Augustinian" method of interpretation, whereby the ECJ consults a number of language versions of a given piece of legislation and then triangulates in order to identify the underlying legislative intent (Solan 2014). Thus, no matter which approach is taken, rather than ascribing meaning to legal concepts on the basis of a single underlying text, the ECJ, by comparing the different language versions of the same legislation, plays the role of mediator between a group of texts in different languages. The ECJ made this position clear in its judgment in Case 6/72 of 13 March $1973^{9}$ on the issuing of advance-fixing certificates for agricultural products stating that

no argument can be drawn either from any linguistic divergences between the various language versions, or from the multiplicity of the verbs used in one or other of those versions, as the meaning of the provisions in question must be determined with respect to their objective.

This position has been confirmed by the ECJ in many subsequent cases, including the well-known CILFIT case $^{10}$. By occupying a space outside the strict letter of the law, the Court is able to leave itself room for manoeuvre to overcome discrepancies between language versions (Biel 2014). Alongside these teleological or contextual approaches, however, the ECJ also continues to use a more literal interpretative approach, giving preference either to the meaning attributed to the majority of language versions or to the language versions deemed the clearest or less ambiguous (Baaij 2012). According to the majority variant the language version(s) which deviate from the majority must be read in accordance with the other versions. The clarity variant requires that the less ambiguous of language versions should be followed (Baaij 2018:

\footnotetext{
9 Case 61/73 Mij PPW Internationaal $N V \quad \mathrm{v}$ Hoofdproduktschap voor Akkerbouwprodukten [1973] ECR 301.

${ }^{10}$ Case 283/81 Srl CILFIT and Lanificio di Gavardo SpA v Ministry of Health [1982] ECR 3415.
} 
Edward Clay \& Karen McAuliffe: Reconceptualising the third space...

168). Consequently, the process and product of legal translation at the ECJ itself occupy the Third Space while the interpretation of EU law undertaken by the Court in the course of its work also occurs within the same Third Space.

\subsection{Third Space Highlighted by Language and Style of the Texts Produced}

\section{a. Hybrid Language}

One of the clearest signs of translation at the ECJ occupying the Third Space is the emergence of new sub-genres of languages brought about as a result of the multilingual processes at work within the organisation. Researchers argue that the large-scale, long-term translation of legislative texts within the EU has led to the emergence of new, hybrid varieties characterised by patterns of usage which differ from standard legal varieties in the various languages involved and are often referred to as "eurospeak" (Robertson 2014: 160) or "eurolects" (Goffin 1994). These varieties emerge from the sui generis multicultural and multilingual contact scenario leading to a convergence on lexical, terminological, structural and textual levels (Mori 2018). In this way, the EU forms "a territory where global (European) meets local (national) to create a hybrid pan-European culture synthesising constituent national cultures" (Biel 2014: 67). This is particularly evident at the ECJ with the appearance of so-called "Court French" - an abstract and opaque variety which differs significantly from 'standard' legal French (McAuliffe \& Trklja 2018). This arises from the fact that those drafting documents in French are not working in their mother tongue and that numerous legal and linguistic compromises need to be struck. The highly formulaic and repetitive nature of the language used in ECJ case law also contributes to the 'Court French' phenomenon (cf. Section 4.1). Over time, this sub-genre has emerged, comprehensible to all those working at the Court, but distinct on various levels from the legal French that is used in national courts.

The Court has its own language, its own French. This makes it easier when you're writing in your second or third language. You just follow the formula. (référendaire); 


\section{Comparative Legilinguistics 45/2021}

Once I know what I want to say in a judgment and have spoken with [the judge rapporteur] I need to write it in French, well the French of the Court. I have my own glossary of phrases the Court uses and work from that. It's not like the French of the Cour de Cassation, believe me! (référendaire, interviewee's emphasis);

On a terminological level, some branches of EU law are still in flux and lack their own supranational terminology (Cavoski 2017). New terms constantly need to be created in the EU context in order to find terms for EU autonomous concepts, to account for new supranational realities (Doczekalska 2009), and to avoid borrowing national terminology, which may lead to ambiguities (Bajcic 2011). Indeed, country-specific legal terms will inevitably result in discrepancies between the language versions (Biel 2014), hence the need for terminologically distinct and culturally neutral EU language varieties. This distinction was highlighted in the CILFIT judgment, which stated that "legal concepts do not necessarily have the same meaning in Community law and in the law of the various member states"11. That terminologically distinct EU legislative language is inevitably reflected in the language of ECJ judgments, which deal with the validity and interpretation of such legislative acts.

Often you have no choice in the language you use because you have to refer to the legislation. If the legislation uses particular terminology you have to use that too. (référendaire);

We're tied to the same terminology that is in the legislation that the case is reviewing. (référendaire).

\section{b. Hybrid Style}

Looking beyond terminology, the format and style of the ECJ's judgments are also a hybrid of the French technique and the more flexible dissertation method (Berteloot 1988). In the first few decades following its inception, the style of the Court's judgments closely mirrored that used in the French Cour de Cassation (Arnull 2018: 907). They were split into two parts containing a small number of very long sentences punctuated by the recurrent phrase "attendu que", with one part setting out the facts and arguments of a case and the other explaining the Court's ruling and its reasoning (Arnull 2018: 907).

\footnotetext{
${ }^{11}$ Case 283/81 Srl CILFIT and Lanificio di Gavardo SpA v Ministry of Health [1982] ECR 3415, para 19.
} 
However, by the late 1970's, with an ever-increasing case load, the style of long sentences was abandoned, and by the 1990's, judgments no longer followed the French Cour de Cassation's approach of setting out separate accounts of the facts and arguments of a case (Arnull 2018: 908). These macro-textual features of style and format serve to further enhance the hybrid nature of the texts produced. It seems that in its quest to produce a homogeneous discourse, the multilingual negotiations which take place within the Court create a blending together of various different linguistic and cultural conventions. However, although the hybrid nature of the language used at the ECJ in both source and translated texts seems clear, the level of hybridity is not necessarily uniform across all EU languages and may be more marked in some languages than in others (Trklja and McAuliffe 2019) ${ }^{12}$.

\section{c. Atypical features}

Far from concealing such hybridity, the atypical elements used in the texts produced by the ECJ serve to highlight the distinct nature of these texts, situating them in a separate sphere from national legal documents. The lawyer-linguists who are then responsible for using these Eurovarieties to translate the ECJ's texts do so in such a way as to remind the reader that the law in question is European law (McAuliffe 2011). It is important that they preserve the unusual features from the source text in the target text rather than opting for more conventional translations which might paper over the 'strangeness' which signposts the origin of this law. Indeed, it is the "foreign element which reveals the interstitial" and "becomes the unstable element of linkage...that has to be engaged in creating the conditions through which newness comes into the world' (Bhabha 2004: 326). In this case, these 'foreign elements' are the atypical linguistic features which occur in all language versions of documents produced by the ECJ. Examples of such features on a lexical level include the use of 'administrative organ' instead of 'board of directors' in EU English (Biel 2014: 64); in EU Dutch, the use of 'asielzoeker' [asylum-seeker] is preferred to 'vreemdeling' [stranger], which is more common in Dutch national legislation and case law (De Sutter \& De Bock 2018: 55); and in EU Italian, there is a preference for the use of 'direttiva' [directive] as opposed to 'decreto'

\footnotetext{
${ }^{12}$ Biel (2014) argues that the textual fit of EU legislative language is likely to be more convergent for procedural languages and more divergent for genetically different languages such as Slavonic or Ugro-Finnic languages.
} 
[decree], which occurs more frequently in domestic law in Italy (Mori 2018: 211). While these examples are taken from research focusing on legislation and studies using corpora consisting of a range of EU text types, they have been cross-referenced with corpora consisting solely of Court judgments (using SketchEngine and the EU Case Law Corpus $)^{13}$. That triangulation verifies that these examples apply equally to ECJ judgments in comparison with national court judgments. These atypical elements serve to alert the reader that the law in question is situated outside the usual sphere of domestic law. In this way, the unusual features contained in the ECJ judgments serve as symbols which flag to the reader that they need to be interpreted in light of the European context in which they have been produced (McAuliffe 2011).

\subsection{Third Space Highlighted by the Status of the Translated Judgment}

Another element which clearly situates translation at the ECJ in a distinct Third Space is the nature and status of the final judgments which the court produces. During their secret deliberations, the judges agree their final judgment in French, which then has to be translated into the language of the case, unless this also happens to be French. In most cases it is therefore usually a translated version of the original judgment which is signed by the judges and which constitutes the single authentic version of the judgment (McAuliffe and Trklja 2018). As a result, the final product of the entire legal process enacted by the court is itself, in the vast majority of cases, a translation. This is in stark contrast to many other legal translation contexts, such as international contract translation, where the original is translated into one or more languages purely for information purposes, while the original always maintains its status as the one authentic and legally-binding text. Indeed, in practice, in most contexts, a translated legal document remains entirely subordinate to its original and very rarely has the status of an authentic text (Garzone 2000). In the case of the ECJ however, the definitive legal judgment is the result of a final act of hybridisation

${ }^{13}$ https://www.sketchengine.eu/; www.llecj.karenmcauliffe.com/euclcorp 
Edward Clay \& Karen McAuliffe: Reconceptualising the third space... through the translation of the French version as agreed in the deliberations.

\section{Challenging the Concept of the Third Space}

Although elements of ECJ legal translation certainly fulfil the criteria of the Third Space in a number of ways, as set out above, translation at the ECJ also challenges that concept. For various reasons discussed below, translation at the ECJ does not conform to the prototypical conception of legal translation as a Third Space. Notions of the Third Space as an undefined, vague and fluid space characterised as a kind of "spacy emptiness" (Spivak 2012: 313) in which linguistic and cultural dynamics can be freely negotiated do not sit easily with the constraints within which translation at the ECJ is carried out. Translation at the ECJ is constrained in both linguistic and legal senses, and, at its core, strives to achieve unity and consistency in EU case law. This section sets out how ECJ translation, in fact, warps that Third Space, and thus should be considered a special case.

\subsection{Language constraints: repetition and formulaicity}

First, a key founding idea of the notion of a Third Space is the theory that

[i]t is that Third Space, though unrepresentable in itself, which constitutes the discursive conditions of enunciation that ensure that the meaning and symbols of culture have no primordial unity or fixity; that even the same signs can be appropriated, translated, rehistoricized, and read anew (Bhabha 1994: 37).

However, the linguistic processes at work within the ECJ are at odds with this idea of constant reinvention and fluidity. Indeed, far from constituting an example of a "protean" and "moving" process (Wagner \& Gémar 2015), ECJ judgments demonstrate a high degree of formulaicity and repetition. For a number of different reasons, there is a strong tendency to constantly repeat the same expressions (McAuliffe 
2015). First, the fact that the majority of référendaires, who draft judgments at least in the first instance, are working in a language that is not their mother tongue, leads in many instances to a reliance on phrases from 'settled case law':

Because I'm not working in [my mother tongue] I rely a lot on what the Court has said before (référendaire);

Lots of what I write is [made up of] stock phrases from the settled case law (référendaire);

It's easier to write in the French of the Court if you follow what it has said before. There are lots of connecting phrases, sentences defining legal principles, the bits around the new part of the judgment, that you can copy over (référendaire, interviewee's emphasis).

Furthermore, there is a perceived pressure to cite previous case law in order to aid or speed up the translation process:

If you use phrases that have been used already in judgments, [those phrases] have also already been translated. It is simpler and quicker in the end. (référendaire);

I feel like there is a certain pressure to use the same sentences from earlier case law to help speed up the process (référendaire).

Also, in the digital age it is quite simply easy, quick, and convenient to find phrases in the 'settled case law' that may fit a particular argument:

Well, it's easy to do a search for the subject of your case and find how the Court has said it before. Why change it? (référendaire).

Finally, it is often argued that since the ECJ is (still) building an EU rule of law, it is necessary to use the same terminology, and formulaic phrases consistently throughout that case law (McAuliffe 2015). However, while it may be legitimately argued that legal language by its very nature needs, to some extent, be formulaic in order to ensure legal consistency, Trklja and McAuliffe's corpus-based study (2019) empirically demonstrated the unusually high level of formulaic expressions used in ECJ judgments in comparison to domestic supreme court judgments. Indeed, the process of drafting judgments is "inherently conservative", with whole phrases remaining untouched from one judgment to another, thus limiting, in the name of linguistic 
consistency, the amount of original drafting which occurs (Arnull 2018: 912).

That formulaic repetitiveness is, naturally, reflected in the subsequent translations. Interestingly, however, the linguistic consistency in the French language version of ECJ judgments is not reflected consistently across all languages (Trklja and McAuliffe 2019). This may be attributable to the relatively late adoption by the ECJ of computer tools (most computers at the ECJ were running MS-DOS operating systems until as late as 2002, with more user-friendly systems, including easily searchable databases being introduced incrementally in the early 2000s), and computer assisted translation tools (The ECJ developed its own matrix known as the Generic Text Interface (GTI) in the late 1990s, which allowed users to incorporate previously translated phrases from earlier case law, and full-function CAT tools were introduced at the ECJ in 2015) In the absence of digital tools, it would have been an extremely difficult task to ensure such consistency across all languages. Conversely, the introduction of CAT tools certainly contributes to repetition and formulaicity in ECJ case law:

With [CAT tools] a lot of the traditional style translating is already done. Since the Court's language is already so formulaic [the CAT tools] can just pull out the relevant phrases, so everything is repeated ad eternum (lawyer-linguist);

Indeed, where référendaires have previously worked as lawyer-linguists (something which is not unusual) CAT tools can exacerbate the repetitive 'cut and paste' approach even before the translation stage:

I was very used to translating the judgments and [CAT tools] were always giving me the same phrases. So when it comes to writing the judgments I already have those phrases. I can search for the translations into French and start from there (référendaire, former lawyer-linguist).

\subsection{The influence of the source language}

As explored above, the original concept of the Third Space, emerging from post-colonial studies, is "embedded in a priori power relations" (Wolf 2000: 134), in which the dominant role may be (but is not 
necessarily) subverted, allowing for "different types of hybridizations" (Wolf 2000: 134). On the surface, therefore, the influence of the source language - French - in ECJ translation would appear to fit with the notion that a language or culture can remain predominant within the Third Space. However, in spite of this, the hierarchical structure of the languages used at the ECJ, and the linguistic processes it follows, produce an outcome which falls outside the scope of what would be expected from any standard interpretation of the Third Space. Indeed, any conception of the Third Space implies some degree of inevitable rebalancing towards the target language or culture, which is constantly counteracted by the predominant position of French at the ECJ. In ECJ case law, French holds a hierarchically superior position over the 22 other languages by virtue of its special status as sole working language of the Court (McAuliffe \& Trklja 2018). Since the founding of the ECJ, its judgments have always been drafted in French and then translated into the other official languages - French has always occupied the source language position for judgments and the other languages have always been in the target position. The relationship between the languages has therefore always been fundamentally unbalanced. This predominance of French undermines the notion of a process of intercultural fertilisation, since French exerts linguistic and cultural influence over all the other languages used. This hierarchical system warps the concept of the Third Space, changing it from a space "located between existing referential systems and antagonisms" (Wolf 2000: 135) to one where a single referential system eclipses all others and the 'antagonisms' impinging on the process, as examined in Section 3 of this paper, are overridden.

As discussed above, in the context of translation, the features of the source language can often manifest themselves in one way or another in the target text. If this phenomenon occurs repeatedly in translations, these features may begin to exhibit themselves with increasing frequency even in non-translated texts in the target language, eventually becoming established in that language (Kranich 2014). In other words, if languages are in contact in a translation scenario for a sufficiently long period and, as is the case in ECJ judgments, the translation direction is always the same i.e. from French, certain features of the target language may change under the influence of the source language, in much the same way that language contact occurs in other settings (cf. Thomason \& Kaufman 1988). This influence of French on EU varieties of other languages can be seen, for instance, in 
the use of certain lexical items in judgments, such as stagiaire and domiciliataire in the English version of judgments, even though English-language terms for these concepts readily exist (Kermas 2010: 56-7). French 'language creep' can also been observed through the Court's references to the Council's or Commission's "legal service" rather than to the legal department or division; "missions" instead of business/work trips; "detached" instead of seconded. Lawyer-linguists are also encouraged not to break up or combine sentences differently from the original French texts. This inevitably means that, as well as the terminology used, the structure of the target texts will also be heavily influenced by the source text, in some cases leading to target texts with unnatural sentence lengths and structures. On top of this, Bobek, Advocate General at the ECJ, argues that such

\footnotetext{
linguistic domination spills over into intellectual domination, which leads to ideas, notions, or solutions from outside the Francophone legal family not being genuinely represented within the institution, and not being systematically translated into its cases (Bobek 2015: 307).
}

Indeed, it appears that the status of French as the working language permeates all aspects of the Court's work putting members who do not have proficient command of French at a disadvantage (Arnull 2018). This predominant position of French in the ECJ's processes has a major impact on the nature of the Third Space in this context, significantly limiting the degree of freedom in the cultural and linguistic negotiation occurring within it.

\subsection{Challenges to the translator's neutral space}

Following Bhabha's initial conception of the Third Space, Spivak further developed the notion within translation studies to envisage translators as "intimate readers" willing to "surrender to the text" (Spivak 2012: 315). Moreover, in her 2005 paper Narratives in and of Translation, Mona Baker discusses the tendency in translation studies discourse to depict translators "as honest and detached brokers who operate largely in the spaces between cultures" (Baker 2005: 11). The notion of the Third Space can therefore tend to envisage a kind of "idealised no-man's land" lying between discrete cultural groupings 
(Baker 2005: 11). Here again, the processes at the ECJ challenge this notion of translation as a Third Space, since the role of the lawyerlinguists responsible for translating the ECJ's judgments differs significantly from that of a conventional translator (McAuliffe 2016). To be eligible to apply for a job as a lawyer-linguist one must have: a law qualification (degree or equivalent, or be qualified to practice as a lawyer in the relevant jurisdiction) from the jurisdiction whose language is the 'target' language (ECJ lawyer-linguists always translate into their mother tongue); a thorough knowledge of at least two other EU languages (one of which should be French); and a good knowledge of EU law. Thus, the majority of the lawyer-linguists working at the ECJ come from a legal background since they need comprehensive knowledge of the various legal systems involved, while also requiring proficiency in a number of EU official languages (McAuliffe 2016). The role of 'lawyer' or 'legal professional' is founded on upholding legal norms, such as the need to remain faithful to the law and ensuring precision so as to avoid ambiguity and uncertainty (McAuliffe 2016). In contrast, the role of the translator inevitably involves a degree of indeterminacy as a result of the culture-bound nature of language. Despite efforts to develop a more precise "science of translating" (Nida 1964) to systematise the translation process and overcome such imprecision, it is widely accepted that the objective of achieving an "equivalent response" through translation is implausible (Hu 1992). The dual roles of lawyer and translator therefore pull in different directions - something which is keenly felt by the ECJ's lawyerlinguists:

Sometimes it's like walking a tightrope. On the one hand I'm a lawyer
and my role is to make sure that the law as set down by the Court is
clear and precise and is exactly what the judges intended. On the other
hand, as a translator, I feel very constrained a lot of the time. Even if I
knew exactly what the judges intended... because, you know, the
deliberations are secret... I don't really have the freedom to get that
message across in the way I would like. My hands are tied to a large
degree (lawyer-linguist).

Bengoetxea goes as far as to say that it is through translation that "genuine multilingual reasoning occurs" at the ECJ. In order to replicate the legal effect of the base French language judgment, discursive interactions between lawyer-linguists and the judges' chambers acquire a new critical dimension (2016). Ideally, judges and their chambers 
should encourage dialogue with lawyer-linguists not just about terminology but also about the most appropriate ways to articulate various arguments in order to ensure uniformity of legal effect across all EU member states. This is unfortunately not always the case: translation is, arguably, perceived more as an obstacle than an asset by the ECJ (Bengoetxea 2016). However, there is little doubt that the remit of the lawyer-linguists at the ECJ goes far beyond a linguistic rendering of texts from one language to another and requires them to juggle the tasks of a translator with the role of legal specialist. Indeed, the vast majority of lawyer-linguists interviewed (14 out of 19) identified as a lawyer 'first' and a translator second. Even those who identified primarily as translators immediately qualified that by pointing out that they were "not just a translator" and/or "a lawyer too". As legal specialists, most lawyer-linguists interviewed view themselves as fulfilling a "checking" or "gatekeeper" role to ensure the correct application of EU law (McAuliffe 2016: 24). The results of such gatekeeping are never visible in the final text of a judgment, but can be very important. For example, it was a lawyer-linguist who, in the Order of the Court in the Saetti and Frediani case $^{14}$, noticed the inconsistent use of the terms réemploi and réutilisation in French, in the context of hazardous waste disposal. If left unchecked, the order could potentially have created a legal loophole in the hierarchy of EU waste management (McAuliffe 2016: 24-25). In that case, the lawyer-linguist in question had to draw upon her expertise as a linguist and her expertise in EU (environmental) law, and intervene to request the relevant judge/référendaire to change the original French language order. Thus, the consequence of the multifaceted role of the lawyer-linguist is that the neutrality of the Third Space, as is frequently inferred in translation studies, is somewhat hindered as they seek to ensure the legal coherence of the texts being translated.

\section{Conclusion}

As this analysis has shown, in many regards, legal translation at the European Court of Justice is consistent with the characterisation of

\footnotetext{
${ }^{14}$ Order of the Court (Third Chamber) of 15 January 2004 in case C-235/02 Criminal Proceedings Against Marco Antonio Saetti and Andrea Frediani [2004] ECR I-1005.
} 
translation as a Third Space. The texts produced at each stage are inevitably hybrid in nature as a result of the complex processes at work within the Court. On both a lexical and textual level, the texts exhibit features which mark them out as distinct and the product of a crossfertilisation of influences from both source and target languages and legal cultures. Indeed, the use of autonomous EU terminology in ECJ judgments has the effect of signposting to the reader that the text occupies a separate space, outside the sphere of national legal texts. Moreover, the teleological approach taken towards legal reasoning at the Court also occupies a space outside the strict confines of the texts involved. Even in the case of the final judgment, the one text which is upheld as authentic and binding is, in most circumstances, a translation. Both the processes and the product of the ECJ's language system therefore appear to bear all the hallmarks of translation as a Third Space. Nevertheless, the specific nature of drafting and the complexities involved in translating at the ECJ place constraints on the Third Space, which means that legal translation at the ECJ must be considered a special case that does not fully conform to the prevailing definitions. Indeed, previous descriptions of translation as a Third Space fail to effectively conceptualise the additional nuances inherent in the case of the environment in which translation at the ECJ occurs. By examining legal translation at the ECJ through the theoretical framework of the Third Space, this paper is ultimately able to highlight the aspects which set it apart from other legal translation contexts.

Rather than constituting a fluid and ever-changing space, the processes in play at the ECJ actively create and perpetuate high levels of formulaic language, which is frequently repeated and reused in documents produced by the Court. The supposed fluidity of the Third Space is thus heavily constrained in this regard, leading to formulaicity where one might expect versatility. Moreover, while the Third Space framework allows for a certain degree of dominance to remain apparent between source and target language, the hierarchical supremacy of French in this case is such that the concept of the Third Space is definitively skewed. Translation at the ECJ places French in an unassailable position of linguistic and legal dominance and constantly acts against any kind of rebalancing that would usually be expected according to the standard notion of the Third Space, which then further limits the linguistic and cultural negotiation that is a central tenet of that notion. Finally, the role of the lawyer-linguist introduces another significant caveat into the standard model of translation as a Third 
Space since the function fulfilled by the lawyer-linguists at the ECJ goes far beyond the typical role of the translator. Instead, lawyerlinguists bring their own legal expertise to the task to ensure the legal coherence of the texts, thus not conforming to the model of the translator as a neutral go-between.

In light of this analysis, the concept of legal translation as a Third Space must be amended and more precisely defined in the context of the ECJ: the concept, thus adjusted, may then be applied to other international or supranational multilingual legal settings on the same basis. This new conceptualisation requires the specific processes and structures within the Court to be taken into account when determining the form and the degree of freedom for linguistic and cultural negotiation within this space. It is insufficient in this context to refer to legal translation as an autonomous and fluid site of intercultural communication since it is impinged upon by various factors related to the institutional processes and the role of the individuals responsible for carrying out the translation. With this in mind, an examination of the ECJ reveals that the dynamics within the Third Space can be altered and warped by the particular characteristics of the translation environment in question. Therefore, although invariably characterised elsewhere as a site for "the negotiation of incommensurable differences" (Bhabha 2004: 312) in which "all forms of culture are continually in the process of hybridity" (Rutherford 1990: 211), the Third Space does not always take the same shape and the dynamics within it do not always entail the same degree of freedom for every type of legal translation. To some extent, the notion of translation as a Third Space is a useful model for conceptualising legal translation at the ECJ, but, as currently articulated, it is unable to fully capture the specificities of legal translation at the Court. In that environment, rather than an amorphous space, the Third Space is better thought of as a determinate area which is delimited by elements of the translation process which place constraints upon it. This adapted framing of the Third Space can consequently be used to better understand and illustrate the dynamics at play in other areas of legal translation where the current concept of the Third Space is equally inadequate for encompassing the specific nature of the translation practices which impact on this space in-between. This analysis also opens up further avenues for the possible exploration of how the Third Space can be shaped and constrained by features of legal translation in other areas outside the ECJ, which in turn will advance our 
understanding of the flexibility and limitations of the notion of a Third Space in a wide range of legal translation environments.

\section{Bibliography}

Ainsworth, Janet. 2014. "Lost in Translation? Linguistic Diversity and the Elusive Quest for Plain Meaning in Law". In The Ashgate Handbook of Legal Translation eds. Le Cheng, King Kui Sin and Anne Wagner, 43-57. Abingdon: Routledge.

Arnull, Anthony. 2018. The working language of the CJEU: Time for a change? European Law Review. 6: 904-919.

Baaij, Jaap. 2018. Legal Integration and Language Diversity: rethinking translation in EU lawmaking. Oxford: Oxford University Press.

Bajčić, Martina. 2011. Conceptualization of Legal Terms in Different Fields of Law: The Need for a Transparent Terminological Approach, Research in Language, 9(1): 81-93.

Baker, Mona. 2005. Narratives in and of Translation. SKASE Journal of Translation and Interpretation. 1(1): 4-13.

Becher, Viktor, Juliane House and Svenja Kranich. 2009. "Convergence and divergence of communicative norms through language contact in translation". In Convergence and Divergence in Language Contact Situations eds. Kurt Braunmüller and Juliane House. 125-152. Amsterdam/Philadelphia: John Benjamins Publishing.

Bengoetxea, Joxerramon, Neil MacCormick and Leonor M. Soriano. 2001. "Integration and Integrity in the Legal Reasoning of the European Court of Justice". In The European Court of Justice. eds. Grainne De Búrca and Joseph H. H. Weiler. 43-85. Oxford: Oxford University Press.

Bengoetxea, Joxerramon. 2016. "Multilingual and Multicultural Reasoning: The European Court of Justice". In Linguistic Diversity and European Democracy. eds. Anne-Lise Kjær and Silvia Adamo. Farnham: Ashgate Publishing.

Berteloot, Pascale. 1988. Babylone à Luxembourg: jurilinguistique à la Cour de Justice. Saarbrücken: Europa-Institut der Universität des Saarlandes. 
Edward Clay \& Karen McAuliffe: Reconceptualising the third space...

Bhabha, Homi K. 1994. The Location of Culture. Abingdon: Routledge. Bhabha, Homi K. 2004. Revised edition. The Location of Culture. Abingdon: Routledge.

Bhabha, Homi K. 2006. "Cultural Diversity and Cultural Differences". In The Post-Colonial Studies Reader, eds. Bill Ashcroft, Gareth Griffiths and Helen Tiffin. 155-157. New York: Routledge.

Biel, Łucja. 2014. Lost in the Eurofog: The Textual Fit of Translated Law. Frankfurt am Main: Peter Lang.

Bobek, Michal. 2015. "Epilogue: Searching for the European Hercules". In Selecting Europe's Judges: A Critical Review of the Appointment Procedures to the European Courts. Oxford: Oxford University Press.

Cao, Deborah. 2007. Translating Law. Clevedon: Multilingual Matters. Čavoški, Aleksandra. 2017. Interaction of law and language in the EU: Challenges of translating in multilingual environment. The Journal of Specialised Translation. 27: 58-74.

Chesterman, Andrew. 2004. "Beyond the Particular". In Translation Universals: Do They Exist? eds. Anna Mauranen and Pekka Kujamäki, 33-50. Amsterdam/Philadelphia: John Benjamins Publishing.

Cronin, Michael. 2000. Across the Lines: Travel, Language, Translation. Cork: Cork University Press.

De Sutter, Gert and Fee de Bock. 2018. Observing Eurolects: The case of Netherlandic Dutch. In Observing Eurolects: Corpus analysis of linguistic variation in EU law. ed. Laura Mori. 4862. Amsterdam/Philadelphia: John Benjamins Publishing.

Doczekalska, Agnieszka. 2009. "Drafting and Interpretation of EU Law - paradoxes of EU multilingualism". In Formal Linguistics and Law. eds. Günther Grewendorf and Monika Rathert. Berlin: De Gruyter Mouton.

Felici, Annarita. 2010. Translating EU law: legal issues and multiple dynamics, Perspectives: Studies in Translatology, 18(2): 95108.

Garzone, Giuliana. 2000. Legal Translation and Functionalist Approaches: a Contradiction in Terms? Paper presented at International Colloquium organized by the School of Translation and Interpretation of the University of Geneva and the Swiss Translators', Terminologists', and Interpreters' 
Association at the University of Geneva, February 17-19, in Geneva, Switzerland.

Goffin, Roger. 1994. L'eurolecte: oui, jargon communautaire: non. Meta. 39(4): 636-642.

House, Juliane. 2006. Covert Translation, Language Contact, Variation and Change. SYNAPS, 19: 25-47.

$\mathrm{Hu}$, Qian. 1992. On the Implausibility of Equivalent Response (Part 1). Meta. 37(2): 289-301.

Kermas, Susan. 2010. "English Legal Discourse and the French Continuum". In Researching Language and the Law: Textual Features and Translation Issues. eds. Davide Simone Giannoni and Celina Frade. 19-48. Frankfurt am Main: Peter Lang.

Koskinen, Kaisa. 2000. Institutional Illusions. The Translator. 6(1): 4965.

Kranich, Svenja. 2014. "Translations as a Locus of Language Contact". In Translation: A Multidisciplinary Approach. ed. Juliane House. 96-115. London: Palgrave Macmillan.

Lawyer-Linguists on the Case Law of the Court of Justice of the European Union. Language and Law / Linguagem e Direito, 3(1): 5-29.

Malamatidou, Sofia. 2016. Understanding translation as a site of language contact: The Potential of the Code-Copying Framework as a Descriptive Mechanism in Translation Studies. Target, 28(3): 399-423.

McAuliffe, Karen and Aleksandar Trklja. 2018. "Superdiversity and the Relationship Between Law, Language and Translation in a Supranational Legal Order". In The Routledge Handbook of Language and Superdiversity. eds. Angela Creese and Adrian Blackledge. 426-441. Abingdon: Routledge.

McAuliffe, Karen. 2008. Enlargement at the European Court of Justice: Law, Language and Translation. European Law Journal. 14(6): 806-818.

McAuliffe, Karen. 2011. Hybrid Texts and Uniform Law? The Multilingual Case Law of the Court of Justice of the European Union. International Journal for the Semiotics of Law. 24: $97-$ 115.

McAuliffe, Karen. 2012. "Language and the Law in the European Union: The Multilingual Jurisprudence of the ECJ". In The Oxford Handbook of Language and Law. eds. Peter M. Tiersma 
Edward Clay \& Karen McAuliffe: Reconceptualising the third space...

and Lawrence M. Solan 200-216. Oxford: Oxford University Press.

McAuliffe, Karen. 2015. Translating Ambiguity. Journal of Comparative Law, 9(2): 49-71.

McAuliffe, Karen. 2016. Hidden Translators: The Invisibility of

Translators and the Influence of Lawyer-Linguists on the Case

Law of the Court of Justice of the European Union. In:

Language and Law/Linguagem e Direito 3(1) 5-29.

McAuliffe, Karen. 2017. "Behind the Scenes at the Court of Justice: A

Story of Process and People" in EU Law Stories. eds. Bill

Davies and Fernanda Nicola. Cambridge: Cambridge University Press.

McAuliffe, Karen, Liana Muntean and Virginia Mattioli. Forthcoming 2021. "Through the Lens of Language: Uncovering the Collaborative Nature of Opinions of Advocates General". In Researching the Court of Justice of the European Union. eds. Mikael Madsen, M, Fernanda Nicola and Antoine Vauchez. Cambridge: Cambridge University Press.

Mehrez, Samia. 1992. "Translation and the Postcolonial Experience: The Francophone North African Text." In Rethinking Translation: Discourse, Subjectivity, Ideology, ed. Lawrence Venuti. 120-38. London/New York: Routledge.

Mori, Laura, ed. 2018. Observing Eurolects: Corpus analysis of linguistic variation in EU law. Amsterdam/Philadelphia: John Benjamins Publishing.

Mori, Laura. 2018. Observing Eurolects: The case of Italian. In Observing Eurolects: Corpus analysis of linguistic variation in EU law. ed. Laura Mori. 200-242. Amsterdam/Philadelphia: John Benjamins Publishing.

Nida, Eugene A. 1964. Toward a Science of Translating. Leiden: E. J. Brill.

Pym, Anthony. 1996. Open letter on hybrids and translation. Http://www.tinet.cat/*apym/on-line/

translation/translation.html. [Accessed on 14 September 2020].

Pym, Anthony. 2001. Against Praise of Hybridity. Across Languages and Cultures, 2(2): 195-206.

Reinharz, Shulamit. 1992. Feminist Methodologies in Social Research. Oxford: Oxford University Press. 
Robertson, Colin. 2014. 'EU Legislative Texts and Translation' In The Ashgate Handbook of Legal Translation eds. Le Cheng, King Kui Sin, and Anne Wagner, 155-176. Abingdon: Routledge.

Rutherford, Jonathan. ed. 1990. Identity: Community, Culture, Difference. London: Lawrence and Wishart.

Šarčević, Susan. 1997. New Approach to Legal Translation. The Hague: Kluwer Law International.

Schäffner, Christina and Beverley Adab. 2001. The Idea of the Hybrid Text in Translation Revisited. Across Languages and Cultures, 2(2): 277-302.

Simon, Sherry. 2011. "Hybridity and Translation". In Handbook of Translation Studies. Volume 2. eds. Gambier, Yves and Luc van Doorslaer, 49-53. Amsterdam/Philadelphia: John Benjamins Publishing.

Snell-Hornby, Mary. 2001. The Space "in Between": What Is a Hybrid Text? Across Languages and Cultures, 2(2): 207-216.

Solan, Lawrence M. 2014. Multilingualism and morality in statutory interpretation. Language and Law / Linguagem e Direito. 1(1): $5-21$.

Spivak, Gayatri C. 2012. "The Politics of Translation," in The Translation Studies Reader, ed. Lawrence Venuti. 312-330. London/New York: Routledge.

Steiner, George. 1998. After Babel: Aspects of Language and Translation. Oxford: Oxford University Press.

Teich, Elke. 2003. Cross-linguistic variation in system and text: A methodology for the investigation of translations and comparable texts. Berlin: de Gruyter.

Thomason, Sarah Grey and Terrence Kaufman. 1988. Language Contact, Creolization, and Genetic Linguistics. Berkeley: University of California Press.

Tirkkonen-Condit, Sonja. 2001. EU Project Proposals as Hybrid Texts: Observations from a Finnish Research Project. Across Languages and Cultures, 2(2): 261-264.

Toury, Gideon. 1995. Descriptive Translation Studies and Beyond. Amsterdam/Philadelphia: John Benjamins Publishing.

Toury, Gideon. 2012. Descriptive Translation Studies and Beyond: Revised Edition. Amsterdam/Philadelphia: John Benjamins Publishing.

Trklja, Aleksandar and Karen McAuliffe. 2019. Formulaic metadiscursive signalling devices in judgments of the court of 
Edward Clay \& Karen McAuliffe: Reconceptualising the third space...

justice of the european union: A new corpus-based model for studying discourse relations of texts. International Journal of Speech, Language and the Law. 26(1): 21-55.

Van Calster, Geert. 1997. The EU's Tower of Babel - The Interpretation of Multilingual Texts by the European Court of Justice. Yearbook of European Law. 17(1): 363-393.

Vareine, Lucile. 2015. Parlez-Vous Eurospeak? Http://www.decodingeurope.com/parlez-vous-eurospeak/ [Accessed on 10 September 2020].

Wagner, Anne and Jean-Claude Gémar. 2014. Communication and culture mediation techniques in jurilinguistics. Semiotica, 201: $1-15$.

Wagner, Anne and Jean-Claude Gémar. 2015. Les enjeux de la jurilinguistique et de la juritraductologie. International Journal for the Semiotics of Law. 28: 1-8.

Wolf, Michaela. 2000. "The Third Space in Postcolonial Representation". In Changing the Terms: Translating in the Postcolonial Era, eds. Sherry Simon and Paul St-Pierre. 127145. Ottawa: University of Ottawa Press. 